\title{
Is Now a Good Time for Iowa to Invest in \\ Cellulosic Biofuels?: A Real Options Approach \\ Considering Construction Lead Times
}

\begin{abstract}
The revised Renewable Fuel Standard of the U.S. mandates a production of 16 billion gallons per year by 2022 from cellulosic biofuels. Iowa, rich in agricultural residues like corn stover, is a major player in contributing to the fulfillment of the cellulosic biofuels mandate. Is it a good time for Iowa to start investing in cellulosic biofuels? Using a fast pyrolysis facility as an example, we present a real options approach for valuing the investment of a new technology for producing cellulosic biofuels subject to construction lead times and uncertain fuel price. We conduct a case study on Iowa, in which the decision maker finds the optimal investment time for the fast pyrolysis facility subject to production and distribution constraints. Our result indicates that the project is profitable if the facility is invested now; but could be
\end{abstract}


more profitable if invested later. Namely, now is not the optimal time for Iowa to start constructing the fast pyrolysis facility. We also find that the impact of the lead time on the project value is too significant to overlook. The profitability of the project is sensitive to the outlook of fuel price. If the future retail fuel price drops just $7 \%$ lower than forecasted by the Energy Information Administration, the investment may not be profitable. The impact of the technology improvement (production yield) and biomass feedstock price is also analyzed using regression.

Keywords: biofuel, fast pyrolysis, facility investment, real options, geometric mean-reverting process

\section{Introduction}

The many eco-benefits of replacing petroleum fuels with biofuels have attracted global attention. For example, biofuels are considered environmentally sustainable for reducing greenhouse gas emissions and air pollution, compared to fossil fuels. The production of biofuels could also assist in regional economic development, especially in rural areas. Furthermore, biofuels could improve energy security through diverse energy sources. Because of these reasons, biofuels have become increasingly popular worldwide, especially in the transportation sector. 
Currently, ethanol and biodiesel are the two main types of biofuels used in transportation. Ethanol is normally blended with gasoline, while biodiesel is used as a substitute for diesel. The fact that these biofuels (e.g., sugar/starchbased ethanol and vegetable oil/soy-based biodiesel) are made by the commodities that can also be used for food limits their capability of substituting petroleum fuels. The production of these traditional biofuels is in competition with the food industry, and the increasing production level has provoked debates about the impact on the food market. In recent years, more focus has turned to developing potential techniques to produce advanced biofuels from non-edible feedstock.

The Energy Independence and Security Act of 2007 (EISA 2007) revised the 2005 Renewable Fuel Standard (RFS) by emphasizing new categories of renewable fuels with greenhouse gas thresholds (EPA 2010). The revised RFS (RFS2) mandates a production of 36 billion gallons per year (BGY) by 2022, from cellulosic biofuels - fuels produced from cellulosic materials, including dedicated energy crops, forestry residues, agricultural residues and urban sources of waste - accomplishing 16 BGY (EPA 2010). According to the U.S. Energy Information Administration (EIA), renewable sources lead in a rise of primary energy consumption. The renewable share of total energy use is expected to increase from $8 \%$ in 2008 to $14 \%$ in 2035 , in response to renewable fuels policies, including EISA 2007 RFS, tax credits for renewable electricity, and RPS programs. In the transportation sector, biofuels account for more than 80 percent of the growth in liquid fuel consumption (EIA 
2010). Unlike conventional biofuels like corn ethanol, cellulosic biofuels are facing difficulties in meeting the requirements of the revised fuel consumption mandates. The U.S. Environmental Protection Agency (EPA) reduced the mandate dramatically from 2010 to 2013 due to the lack of sufficient production capacity of cellulosic biofuels (CRS 2013).

Iowa is an agricultural state where biofuels, especially corn ethanol and soy biodiesel, are mostly produced using traditional agricultural crops. In addition to federal support and regulations on biofuel usage, Iowa state government also provided financial incentives for the production and usage of biofuels, including a biodiesel blend retailer tax credit, a biodiesel producer tax refund, alternative fuel production tax credits, and biofuel infrastructure grants. On the other hand, Iowa is also rich in agricultural residues like corn stover (as shown in Figure 1), which can contribute to the fulfillment of the RFS2 cellulosic biofuels mandate if the residues can be utilized with productive processes.

To increase the production level of cellulosic biofuels to meet the RFS2 mandates in future years, various studies on different cellulosic biofuel pathways, producing cellulosic ethanol, and biomass-to-liquid fuels, have been conducted. In general, cellulosic biofuels can be made through hydrolysis and fermentation, gasification and further conversion, or liquefaction with further upgrading of cellulose materials. So far these advanced biofuel processing approaches face excessive costs due to low energy density of solid biomass, and highly dispersion of biomass with rather low annual yields. 



Figure 1: Corn stover distribution in Iowa

Fast pyrolysis (or flash pyrolysis), is a thermochemical process that heats compact solid biomass in the absence of oxygen at a temperature between 450 and 500 degrees Celsius, followed by a very rapid cooling and condensing of produced vapor to generate high yields of pyrolysis oil with roughly half the heating value of fossil fuels. This process can serve as a pre-treatment step, creating a uniform, liquid intermediate product with significant increase in energy density. Pyrolysis bio-oil could be produced at a practical scale, matching the amount of biomass collection within reasonable costs. The intermediate product from fast pyrolysis could then be stored and shipped cost-effectively to a central site for further conversion to desirable final products, such as industrial heat, electricity, chemicals, and transportation fuels. 
Details of fast pyrolysis technology are available in literature (e.g., Bridgwater 1999, 2002, 2005; Piskorz et al. 1988; Babu 2008; Wright et al. 2010).

Currently, fast pyrolysis technology is starting to gain technology efficiency and going commercial scale. Some companies in the U.S. and Canada are attempting to commercialize the technology and hope to convert biomass (such as wood residues) to transportation fuels with a high yield.

Before any biofuels technologies can be utilized in commercial applications, evaluating the economic feasibility is inevitable. One typical and often adopted method is the techno-economic analysis (TEA). In such analysis, the technical aspects of the project are developed based on experimental results with performance of mass and energy balance. And the economic aspects determine the fixed and variable costs of project investment, as well as fuels production (Swanson et al. 2010). The TEA study on fast pyrolysis and hydroprocessing technology suggests this pathway to be economically feasible, attaining a minimum fuel selling price (MFSP) of $\$ 2.57 /$ gal gasolineequivalent (gge) (Brown et al. 2013). However, the TEA method is rather primitive and does not account for risk and uncertainty or the flexibility of decision-making, which we argue are too important to overlook.

In this paper, we use a real options approach to value the irreversible investment of a pyrolysis facility in Iowa subject to a construction lead time and uncertain fuel price. Real options valuation is known to be able to capture the value of flexibility that arises in the decision-making and operational processes. It has been used in valuing a wide range of investments in natural 
resources, real estate, R\&D and manufacturing, etc. Different types of real options, such as options to defer, abandon, and alter operating scale, are discussed extensively in literature (e.g. Cortazar et al. 1998, Huchzermeier and Loch 2001, Bengtsson and Olhager 2002, Dimakopoulou et al. 2014).

Recently, as renewable energy became popular, real options approaches have also been utilized in the investments of renewable resources. Such applications involve valuing the real options associated with investment strategies and/or obtain insights on policy planning. Bockman et al. (2008) used a real options approach to value continuous investment of small hydropower plants subject to uncertain prices. Lee and Shih (2010) evaluated the renewable energy policy for developing renewable energy in Taiwan using the concept of policy return on investment (PROI). With the analysis, it is found that a higher feed-in tariff policy does not necessarily impact PROI and policy benefit positively, and internalizing external costs does not necessarily impact PROI negatively. Chen and Tseng (2011) compared two policies, tax and cap-and-trade, to see which policy would induce an earlier adoption of clean technology. Under each policy, the investment timing of clean technology was determined using a real-options approach. Boomsma et al. (2012) proposed a real options approach to investigate investment timing and capacity choice of a renewable energy project under different support schemes including feed-in tariffs and renewable energy certificate trading. Cook and Lin (2014) used a dynamic structural econometric model to examine shutdown and upgrade decisions of wind turbine owners in Denmark. 
Bioethanol plant investment has also been valued using real options. Schmit et al. (2011) investigated the effects of the U.S. ethanol policy on a firm-level investment decision on an infinite time horizon. Maxwell and Davison (2014) extended the analysis of Schmit et al. (2011) by considering entry into the project within a finite time horizon and looking into the optimal operation once the project is initiated. Lin and Thome (2014), Lin and Yi (2014a) and Lin and Yi (2014b) employed a structural econometric model of a dynamic game to analyze the decision to invest in ethanol plants of corn or various feedstocks in the U.S., Canada and Europe, respectively. Furthermore, Yi, Lin and Thome (2014) analyzed the effects of government policy on entry, exit, investment, and production decisions of ethanol producers in the U.S. These papers focus on bioethanol production. The technology for producing bioethanol is rather mature with data on plant investment, operations and productions available. In this paper we value a cellulosic biofuel facility that will produce liquid transportation fuels. In our case, the production technology is still in an infant stage of commercialization, with very limited plant data available.

In this paper, we present a risk-neutral valuation method for the investment of a new technology for producing cellulosic biofuels. A real options approach is used to value the investment subject to a construction lead time and uncertain fuel price. We conduct a case study on Iowa, in which the decision maker (DM), finds the optimal investment time for the fast pyrolysis facility subject to production and distribution constraints. Furthermore, we 
use regression analysis to study the impact of the technology improvement (production yield) and biomass feedstock price.

The contributions of this paper are twofold. In terms of the application, we are the first paper to use real options to value a pyrolysis plant, which is an emerging technology for producing advanced biofuels. Our analysis sheds light on the profit and risk of the investment of cellulosic bioenergy production, which has an impact on the sustainable future of the nation's renewable energy development. In terms of the methodology, we incorporate the operational constraints that impact the valuation and are constantly overlooked by other researchers. These operational constraints include the construction lead time and the production and distribution constraints. As we will demonstrate in this paper, overlooking these constraints, especially the lead time, will lead to a significant overvaluation of the asset, which should be avoided in evaluating an investment decision.

The remainder of the paper is structured as follows. Section 2 models the fast pyrolysis facility investment as a multi-stage stochastic programming problem. We present the solution procedure in Section 3. We discuss the results from the case study in Section 4. Section 5 concludes the paper.

\section{Problem Formulation}

In this paper, the fast pyrolysis facility owner purchases cellulosic biomass from farmers and converts it to hydroprocess bio-oil at the facility with 
fast pyrolysis and simple hydrotreating. The hydroprocessed bio-oil is then shipped to an existing biorefinery. After further conversion, including hydrocracking and refining, the hydroprocessed bio-oil is converted to final products, such as liquid transportation fuels (gasoline and diesel). For simplicity, we consider one transportation fuel (gasoline) as the output of the pyrolysis process in this paper. The facility owner ships and sells the transportation fuel to distributed customers. Besides the transportation fuel, the fast pyrolysis process also produces by-products (primarily fuel gas). Because the revenues from the by-products are relatively small compared with the revenue from the transportation fuel, we do not consider the by-products in this paper. The supply chain, from feedstock input to fuel output at customers, is depicted in Figure 2.

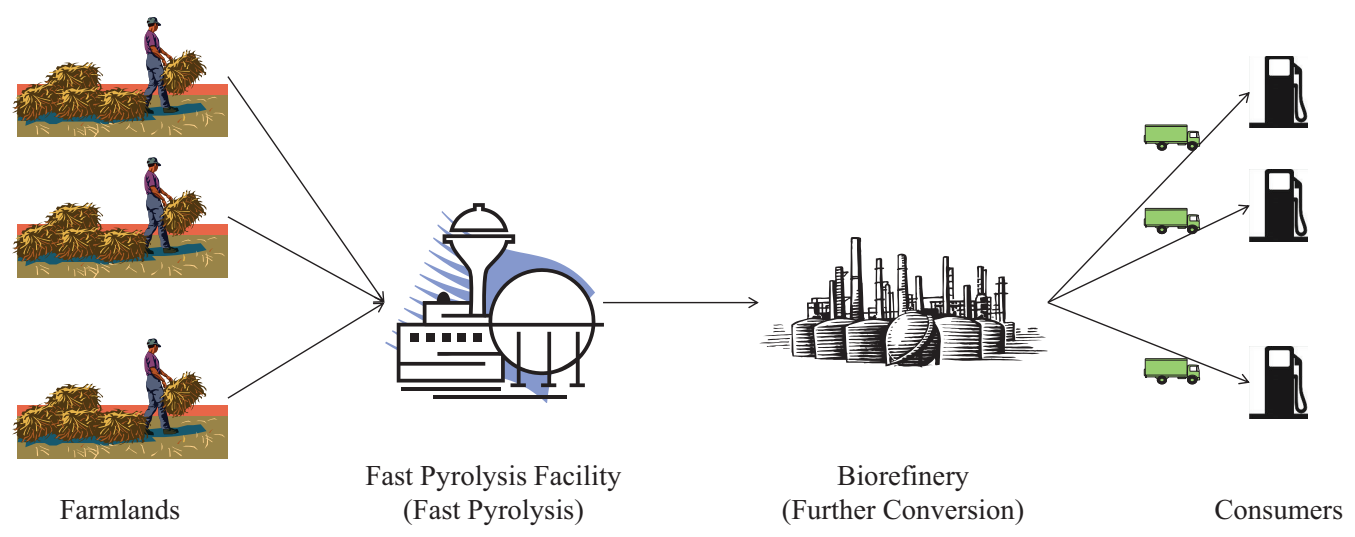

Figure 2: Biofuel production from fast pyrolysis and further conversion

Assume that the DM is considering building a new fast pyrolysis facility at a pre-determined location in Iowa. Our focus is to value the project 
considering the optimal investment timing. First we introduce the notation to be used in the model.

\section{Notation}

$t \quad$ index for time (month)

$i \quad$ index for gasoline demand locations $(i=1,2, \ldots, N)$

$L \quad$ construction lead time for the facility (month)

$\tau \quad$ unknown future investment time (month)

$T$ the length of the planning horizon (month)

$\hat{T} \quad$ the length of the decision period (month)

$I_{t} \quad$ capital cost of a fast pyrolysis facility at $t(\$)$

$\theta_{1} \quad$ conversion rate from dry basis biomass to hydroprocessed bio-oil

$\theta_{2}$ conversion rate from hydroprocessed bio-oil to transportation fuels

$Q_{t} \quad$ decision variable for biomass operating level (metric ton)

$Q^{\max }$ maximum biomass operating capacity (metric ton)

$q_{i t} \quad$ quantity of fuel output shipped from biorefinery to demand location $i$ at time $t$ (metric ton)

$d_{i t} \quad$ fuel demand at location $i$ at time $t$ (metric ton) 
$P_{t} \quad$ fuel market price at time $t(\$ /$ gallon $)$

$H_{t} \quad$ threshold price for fuel at time $t$ (\$/gallon)

$C^{B} \quad$ biomass feedstock price $(\$ /$ dry metric ton $)$

$C^{O} \quad$ unit operating cost $(\$ /$ gallon $)$

$C^{H} \quad$ shipping cost for hydroprocessed bio-oil (\$/metric ton-mile)

$C^{F} \quad$ shipping cost for fuel (\$/metric ton-mile)

$C^{T}$ fuel tax $(\$ /$ gallon $)$

$l \quad$ shipping distance from fast pyrolysis facility to biorefinery (mile)

$\ell_{i} \quad$ shipping distance from biorefinery to the $i$-th demand location (mile)

The major underlying uncertainty of this project valuation is the fuel price $P_{t}$. The other uncertainties, such as production technology (biofuel yield) and biomass feedstock price, although also important to the valuation, are not as volatile as the fuel price. Because the biomass supply chain is still being developed, there are limited data for them. Therefore, we focus on the major uncertainty of the fuel price and treat the other uncertainties as parameters rather than stochastic variables. Their effects on the investment decision and timing will be studied using regression analysis in the case study. Assume that $P_{t}$ evolves according to the following stochastic process.

$$
d P_{t}=\mu\left(P_{t}, t\right) d t+\sigma d B_{t}
$$


where $B_{t}$ is a Wiener process, $\mu$ is the drift function, and $\sigma$ is the volatility. The cash flows associated with the biofuel production at time $t$ include revenue from fuel sales $R_{t}\left(Q_{t} ; P_{t}\right)$ and operating costs incurred $C_{t}\left(Q_{t}, \mathbf{q}_{t} ; P_{t}\right)$, where $\mathbf{q}_{t} \equiv\left(q_{1 t}, q_{2 t}, \cdots, q_{N t}\right)$ is a vector of the quantities of fuel shipped to all demand locations at time $t$. Let $\pi_{t}(\cdot)$ denote the total profit at time $t$. We have

$$
\pi_{t}\left(Q_{t}, \mathbf{q}_{t} ; P_{t}\right)=R_{t}\left(Q_{t} ; P_{t}\right)-C_{t}\left(Q_{t}, \mathbf{q}_{t} ; P_{t}\right)
$$

The revenue $R_{t}(\cdot)$ can be represented by

$$
R_{t}\left(Q_{t} ; P_{t}\right)=P_{t} \theta_{1} \theta_{2} Q_{t}
$$

where $\theta_{1} \theta_{2} Q_{t}$ is the output quantity of the biofuel production process, as illustrated in Figure 3.



Figure 3: Illustration of the biofuel production process and the incurred costs

Figure 3 also shows the cost components incurred in different stages of 
the production process, including biomass purchase cost, facility operating cost, transportation fees of hydroprocessed bio-oil and gasoline, and fuel tax. In the valuation, we focus on the investment of the fast pyrolysis facility, not including the biorefinery plant because the refinery technology is mature and its production process is very predictable. Note that the facility operating cost considers conversion costs at both the fast pyrolysis facility and biorefinery. The sum of all these cost components is denoted by $C_{t}(\cdot)$ as follows.

$$
C_{t}\left(Q_{t}, \mathbf{q}_{t} ; P_{t}\right)=C^{B} Q_{t}+C^{H} \theta_{1} Q_{t} l+C^{O} \theta_{1} \theta_{2} Q_{t}+\sum_{i=1}^{N} C^{F} q_{i t} \ell_{i}+C^{T} \theta_{1} \theta_{2} Q_{t}
$$

In (4), the facility operating level $\left(Q_{t}\right)$ and the product distribution quantities $\left(q_{i t}\right)$ are decision variables, subject to the following operating constraints:

$$
\begin{aligned}
Q_{t} & \leq Q^{\max } \\
q_{i t} & \leq d_{i t}, \forall i \\
\sum_{i=1}^{N} q_{i t} & =\theta_{1} \theta_{2} Q_{t} \\
Q_{t}, q_{i t} & \geq 0, \forall i, t
\end{aligned}
$$

Equation (5) shows the plant capacity limitation. Equation (6) implies that the amount of fuel products delivered to a location does not exceed the demand level, and (7) is the conversion balance constraint.

At each time $t$, the facility finds its optimal operating decisions $\left(Q_{t}^{*}, \mathbf{q}_{t}^{*}\right)$ 
based on the fuel price $P_{t}$ at time $t$ by solving:

$$
\left(Q_{t}^{*}, \mathbf{q}_{t}^{*}\right)=\arg \max _{Q_{t}, \mathbf{q}_{t}}\left\{\pi_{t}\left(Q_{t}, \mathbf{q}_{t} ; P_{t}\right):(5)-(8)\right\}
$$

Let the project value for investing in the fast pyrolysis facility be denoted by $F\left(P_{0}\right)$, where $P_{0}$ is the current fuel price. We want to maximize its expected net present value (NPV) as follows:

$$
F\left(P_{0}\right)=\max _{\tau \in[0, \hat{T}]} E\left[-I_{\tau} e^{-r \tau}+\int_{\tau+L}^{T} e^{-r s} \pi_{s}\left(Q_{s}^{*}, \mathbf{q}_{s}^{*} ; P_{s}\right) d s\right]^{+},
$$

where $E$ is the expectation operator, $r$ is the discount rate, $\tau$ is the future investment time, and we use the notation $x^{+} \equiv \max (x, 0)$. In (10) $I_{\tau}$ is the equivalent (one-time) capital cost of the pyrolysis facility incurred at time $\tau$, which is equal to the worth of all the (monthly) debt repayments at time $\tau$. In (10) we maximize the expected NPV of the total profits (made through the operations of the pyrolysis facility) over a fixed planning horizon $[0, T]$ (e.g., $T=20$ years). Equation (10) also describes that the facility requires $L$ time periods to become operational. This lead time $L$ may include the time required for construction, environmental evaluation, and permitting.

Figure 4 shows the cash flows associated with the investment. This investment problem is somewhat similar to valuing an American call option on a dividend-paying stock at a prespecified price. In this context, $\hat{T}$ represents the expiration date of this call option. By exercising the call option, the DM buys the stock, which corresponds to constructing the facility. The div- 
idends correspond to the profits $\pi_{t}$ generated by the facility. However, there are two major differences from valuing a call option in reality. First, there is a delay of $L$ time periods between the time that the option is exercised and the time that the ownership of the stock is successfully transferred to the option holder. Second, the stock loses its value after $T$. The reasons for the design of having a finite $T$ and $\hat{T}$ are further elaborated in the next paragraph. Our problem is to determine the optimal timing for exercising the above call option.

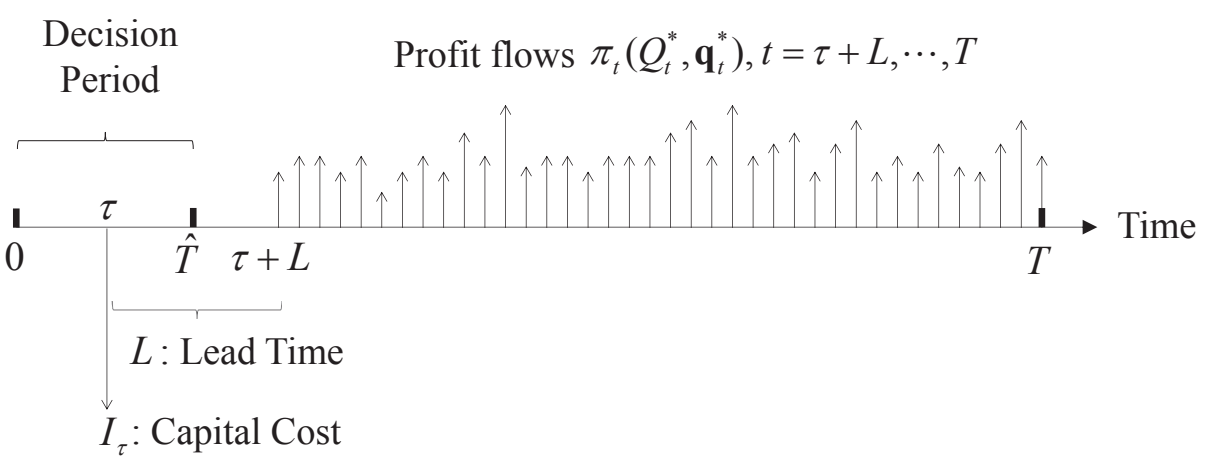

Figure 4: The cash flows of the investment

As shown in Figure 4, the investment time $\tau$ is only considered over a decision period $[0, \hat{T}]$, where $\hat{T}$ is chosen to be much smaller than the fixed planning horizon $T$. We choose $T=20$ years and $\hat{T}=5$ years in our case study. This design has practical reasons. First, if $\mathcal{L}$ is the life of the facility, the life cycle of the facility starts at $\tau$ and ends at $\tau+L+\mathcal{L}$. This duration of life varies with $\tau$, which complicates the analysis. To simplify, we focus 
on all the cash flows occurring within $[0, T]$ (20 years), regardless of $\tau$. That means the cash flows occurring beyond $T$ are truncated. Second, since we are limiting the value of $T$, the option for investing in the facility should not be long-lived. Furthermore, by limiting the decision period to be less than 5 years, we also ensure that the present value of the truncated cash flows that occur beyond $T$ is not significant.

Furthermore, investing in a facility is a big decision. Instead of assuming that the investment decision is evaluated continuously over time, it is more reasonable to assume that the investment decision is evaluated periodically (e.g., at the beginning of each month) until it is made. That is, we assume the investment time $\tau$ is an integer over $[0, \hat{T}]$. It is also possible that the project may not be profitable and, therefore, the facility may not be built and the project value is zero. This possibility is also accounted for in the formulation.

\section{Optimal Investment Timing}

The investment timing $\tau$ in (10) is a random variable if the facility is not built immediately at time 0 . Therefore, if $\tau>0$, the (future) investment decision simply depends on the fuel price $P_{\tau}$ at $\tau$, which is uncertain. Intuitively, at each time $t$ there is a threshold price, denoted by $H_{t}$, such that building the facility is optimal if $P_{t} \geq H_{t}$; otherwise, it is better off to wait.

In general, a threshold price is not the break-even price at which the 
project value is zero. It is well known in literature that waiting has value (e.g., Dixit and Pindyck 1994). In this case, the effects of delaying the investment of the pyrolysis plant are twofold. First, it delays the disbursement of the capital, which earns interest. Second, it also delays the time that the facility starts to collect revenues. The future revenues depend on the evolution of fuel price $P_{t}$. To make it more complicated, the future costs may also increase (e.g., labor or materials costs) if the project is delayed. However, for a new technology, such as the biofuel pyrolysis plant considered in this paper, delaying the investment may allow the DM to adopt a newer technology (e.g., with a higher yield) later. Therefore, even if building the facility immediately can yield a positive project value, it may not be immediately clear whether delaying the project would be better off. In this paper, we do consider that the capital cost $I_{t}$ may change over time. While we do not consider the evolution of the new technology, we will later use regression analysis to estimate the effect of the pyrolysis yield to the project value. Next we discuss our approach for solving (10).

\section{The Solution Procedure}

To solve (10), the key is to determine the threshold prices at all possible decision-making points. Our approach is to approximate the continuous process of $P_{t}$ in (1) by a discrete price lattice (such as a binomial or trinomial lattice). We use a trinomial lattice as it is able to handle the processes with a drift function that is state dependent (e.g., a mean-reverting process whose 
drift $\mu$ is a linear function of $P_{t}$ ).

To approximate a continuous process using a discrete lattice, we use a small step size $\Delta t$, for building the lattice, noting that an investment decision can only be made at certain time periods (e.g., corresponding to the beginning of each month before $\hat{T}$ ). Then using backward stochastic dynamic programming (SDP) steps, we can obtain the project value at time 0 .

After the entire lattice has been evaluated (from $T$ to 0 backward), for each time $t$ where an investment decision is available, we collect the information associated with each lattice node $(j=1, \cdots, J):\left\{\left(P_{t}^{j}, G_{t}^{j}\left(P_{t}^{j}\right), F_{t}^{j}\left(P_{t}^{j}\right)\right)\right\}_{j=1}^{J}$, where $P_{t}^{j}$ is the price of node $j$; and $G_{t}^{j}\left(P_{t}^{j}\right)$ is the corresponding value-to-go at node $j$ representing the cumulative project value from $t$ to $T$ when the fuel price at node $j$ is $P_{t}^{j}$ assuming that the facility has been in place. That is,

$$
G_{t}^{j}\left(P_{t}^{j}\right)=E\left[\sum_{s=t+L}^{T} e^{-r(s-t)} \pi_{s}\left(Q_{s}^{*}, \mathbf{q}_{s}^{*} ; P_{s}\right)\right]
$$

We use $F_{t}^{j}\left(P_{t}^{j}\right)$ to represent the cumulative project value at node $j$ from $t$ to $T$ when the fuel price at $t$ is $P_{t}^{j}$ as follows.

$$
F_{t}^{j}\left(P_{t}^{j}\right)= \begin{cases}\max \left\{G_{t}^{j}\left(P_{t}^{j}\right)-I_{t}, e^{-r} E\left[F_{t+1}\left(P_{t+1}\right)\right]\right\} & t<\hat{T} \\ \max \left\{G_{t}^{j}\left(P_{t}^{j}\right)-I_{t}, 0\right\} & t=\hat{T}\end{cases}
$$

It can be seen in (12) that the DM faces two alternatives at each time $t$ : to invest immediately or to wait. Consider the difference of the values associated 
with these two alternatives, and denote it by $D_{t}^{j}\left(P_{t}^{j}\right)$ as follows.

$$
D_{t}^{j}\left(P_{t}^{j}\right)= \begin{cases}G_{t}^{j}\left(P_{t}^{j}\right)-I_{t}-e^{-r} E\left[F_{t+1}\left(P_{t+1}\right)\right] & t<\hat{T} \\ G_{t}^{j}\left(P_{t}^{j}\right)-I_{t} & t=\hat{T}\end{cases}
$$

We then regress $\left\{D_{t}^{j}\left(P_{t}^{j}\right)\right\}_{j=1}^{J}$ on $\left\{P_{t}^{j}\right\}_{j=1}^{J}$ to obtain a functional relationship $\tilde{D}_{t}\left(P_{t}\right)$. The threshold price $H_{t}$ is where $\tilde{D}_{t}(\cdot)$ intersects with the price axis. That is, $\tilde{D}_{t}\left(H_{t}\right)=0$. This process is illustrated in Figure 5, from which it becomes clear that when $P_{t} \geq H_{t}$ at time $t$, it is optimal to build the facility immediately; otherwise it is better off to wait.

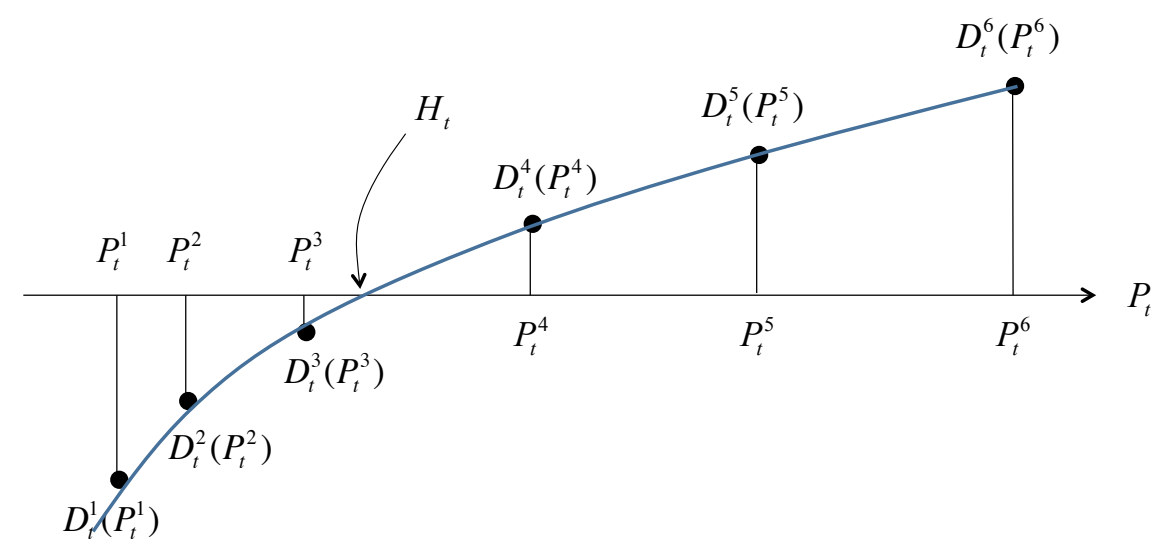

Figure 5: Using regression to obtain the threshold price $H_{t}$ at time $t$

In the last step we use Monte Carlo simulations to determine the distribution of the optimal investment time $\tau$. Given the threshold prices obtained $H_{t}, t=1, \cdots, \hat{T}$, one can generate sample price paths $\left\{P_{t}^{(k)} \mid P_{0}^{(k)}=P_{0}, k=\right.$ $1, \cdots, K\}$ that approximate $(1)$, where the superscript $k$ is the index of sim- 
ulation runs. In the $k$-th simulation run, the corresponding investment time, denoted by $\tau^{(k)}$, is the first time when the simulated fuel price is greater than the threshold price. That is,

$$
\tau^{(k)}=\min \left\{t \mid P_{t}^{(k)} \geq H_{t}, t=0,1,2, \cdots, \hat{T}\right\}
$$

Then we can estimate the (discrete) distribution of the investment time $\tau$. The expected optimal investment time (or delay) is estimated by

$$
E[\tau]=\frac{\sum_{k=1}^{K} \tau^{(k)}}{K}
$$

\section{Case Study}

In this section we present a case study to demonstrate the proposed valuation approach. Although the case is fictitious, all parameter values used here are obtained from literature and are believed to be close to those in reality.

\subsection{Modeling Price Uncertainty}

The general form of the fuel price is described in (1). In this case study, we use the following geometric mean-reverting (GMR) process to capture the 
evolution of the fuel (gasoline) price.

$$
d \ln P_{t}=\lambda_{t}\left(m_{t}-\ln P_{t}\right) d t+\sigma_{t} d B_{t}
$$

where $\lambda_{t}$ is the reverting coefficient, $m_{t}$ is the mean level of gasoline price at time $t, \sigma_{t}$ is the volatility, and $B_{t}$ is a Weiner process.

Cellulosic biofuels production is still in an early stage of commercialization. There are currently no derivative markets trading cellulosic biofuels. To estimate the process of the fuel price, we turn to the gasoline retail prices published by the U.S. EIA.

Using the historical data of monthly retail gasoline prices of the Midwest region, obtained from the EIA (EIA 2013a), we estimate the values of the parameters, $\lambda_{t}, m_{t}$, and $\sigma_{t}$ in (16). The historical price data are depicted as the solid line, ranging from 1994 to 2014, in Figure 6. On the other hand, EIA has also provided its forecast on the annual retail price up to 2040 (EIA 2013b), shown in Figure 6 as the dashed line. The price parameter $m_{t}$ is estimated with a polynomial regression over historical and predicted gasoline retail prices from 1994 to 2040 to capture the fuel price trend, and the fitted values of $m_{t}$ as shown in Figure 6 with the dotted line. The values of $m_{t}$ for the next 20 years are given in Table 1 . Note that in determining the trend of the mean price $m_{t}$, there is no specific monthly or seasonal patterns observed. As a result, we have one mean value $m_{t}$ for each year in Table 1. The values of $\lambda_{t}$ and $\sigma_{t}$ are estimated based on a fitted $m_{t}$ using the 
method of maximum likelihood (e.g., Tseng and Barz 2002). Since there are no sufficient data to support a monthly or annual $\lambda_{t}$ and $\sigma_{t}$, we have a constant $\lambda$ and $\sigma$ for the entire planning horizon. The fitted values of all price parameters are listed in Table 1.

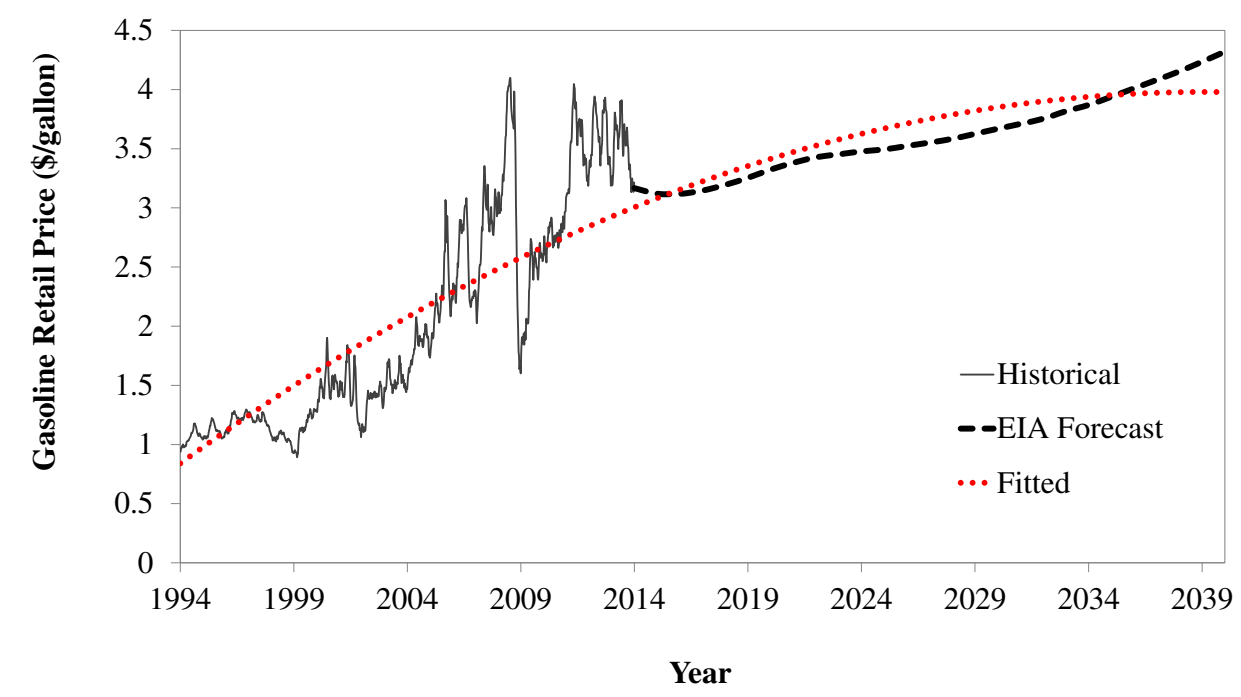

Figure 6: Mean price estimation

Table 1: Values of GMR process parameters

\begin{tabular}{lrrrrrrrrrr}
\hline \multicolumn{1}{c}{$\lambda_{t}=0.0700$} & \multicolumn{1}{c}{$\sigma_{t}=0.0781$} \\
\hline Year & 2015 & 2016 & 2017 & 2018 & 2019 & 2020 & 2021 & 2022 & 2023 & 2024 \\
\hline$m_{t}$ & 1.09 & 1.11 & 1.13 & 1.15 & 1.16 & 1.18 & 1.19 & 1.20 & 1.21 & 1.22 \\
\hline Year & 2025 & 2026 & 2027 & 2028 & 2029 & 2030 & 2031 & 2032 & 2033 & 2034 \\
\hline$m_{t}$ & 1.23 & 1.24 & 1.24 & 1.25 & 1.26 & 1.26 & 1.26 & 1.26 & 1.26 & 1.26 \\
\hline
\end{tabular}

Under the risk-neutral valuation paradigm, we set the discount rate $r$ to the risk-free rate $r_{f}$ in (10)-(13). The price process (16) is also riskneutralized by subtracting the normalized risk-premium from the mean level 
of the gasoline price. The risk-neutral price process then has a drift function $\lambda_{t}\left(m_{t}-\left(r_{a}-r_{f}\right) / \lambda_{t}-\ln P_{t}\right)$, where $r_{a}$ is the risk-adjusted discount rate (Schwartz and Smith 2000).

Given the risk-neutral GMR process for the fuel price, we use the trinomial price lattice proposed in Tseng and Lin (2007) to approximate this process. Similar to the lattice developed by Hull and White (1993), the lattice nodes in our implementation are predetermined and fixed. Each lattice node maps to three adjacent nodes in the next time period following certain branching patterns. The branching probabilities are then determined such that the mean and the variance of the price change are matched. This method is straightforward in handling processes with general drift functions, including our case where the mean level $m_{t}$ is time dependent. A brief review of the trinomial lattice is given in the Appendix.

Since our historical data are monthly prices, the parameters are estimated on a monthly basis. In our implementation, we use a time step size of the lattice being $\Delta t=1 / 30$, corresponding to each day, to better approximate the continuous price process.

\subsection{Data Sources}

The candidate location for the fast pyrolysis facility is assumed to be at the center of Story County, Iowa. To fulfill the volume requirement of cellulosic biofuels in RFS2, large-scale productions of biofuels would be the future trend. Iowa, as a state rich in biomass supply, will play an important 
role. Thus, a local biorefinery is assumed to be constructed for economic efficiency, compared with outsourcing the refining process to out-of-state refineries. The location of the refinery is considered to be the center of Kossuth County, which maximizes the long-term profit of the whole biofuel production in Iowa ( $\mathrm{Li}$ et al. 2014). Overall, these two pyrolysis and refinery facilities will provide gasoline to the businesses and residents in Iowa.

The gasoline demand in Iowa is considered of a metropolitan statistical areas (MSAs) level, while the demand location is modeled at all MSA centers. The demand (quantity) is assumed to be proportional to the population. The total gasoline demand of Iowa is obtained from EIA, using 2011 state-level gasoline consumption statistics (EIA 2013c), and the population of Iowa MSAs is from U.S. Census Bureau 2013 (US Census Bureau 2013).

Since Iowa is an agricultural state rich in corn production, the residues, corn stover is considered to be the feedstock of the plant. Assume the facility purchases corn stover from local farmers at $\$ 58.5 /$ dry metric ton, which includes delivery cost (OEERE 2011).

The technology data are based on the revised TEA of a fast pyrolysis plant with bio-oil upgrading using 2,000 metric tons per day (MT/day) of corn stover feedstock (Brown et al. 2013). The main products after fast pyrolysis, bio-oil upgrading and refining are naphtha-range and diesel-range fuels, which can be used in the transportation sector. The fuel amount is measured by gasoline gallon equivalent. The unit operating $\operatorname{cost} C^{O}$ of liquid fuel for such a facility is $\$ 1.091 /$ gallon excluding feedstock cost. The bio-oil 
conversion rate $\left(\theta_{1}\right)$ from dry basis corn stover feedstock is 0.63 , and the fuel conversion rate $\left(\theta_{2}\right)$ from bio-oil is 0.414 . Capital cost $\left(I_{t}\right)$ is estimated to be $\$ 429$ million that increases by an inflation rate of 1.5\% per year (BLS 2014). A tax credit from facility depreciation is also included.

The transportation method chosen for hydrotreated bio-oil and gasoline is by truck. The variable transportation cost $\left(C^{H}\right.$ and $\left.C^{F}\right)$ is assumed to be $\$ 0.26 /$ ton-mile, the national average truck shipping cost (BTS 2012). The shipping distances are estimated by great circle distances, which are the shortest distance between any two locations on a sphere, modified by a circuity factor. The circuity factor for truck transportation mode is 1.22 (CBO 1982).

When estimating the profit from fuel production, the excise tax imposed on the fuel sale must be included. The fuel tax of gasoline is assumed to be $\$ 0.404 /$ gallon, which is the fuel tax rate in Iowa in 2013 (API 2013).

We set the risk-free interest rate to be $5 \%$ because the average long-term U.S. treasury yield over the last 20 years (from 1995 to 2014) is approximately 5\% (US Treasury 2014). The risk-adjusted discount rate reflecting the DM's risk preference is set to be $r_{a}=10 \%$. We also assume the project is financed by a commercial loan with a loan rate of $7.5 \%$, which is consistent with that used in Brown et al. 2013.

A summary of major model parameter values is listed in Table 2 . 
Table 2: Values of model parameters

\begin{tabular}{lll}
\hline Notation & Value & Source \\
\hline$\theta_{1}$ & 0.63 & Brown et al. (2013) \\
$\theta_{2}$ & 0.414 & Brown et al. (2013) \\
$I_{t}$ & $\$ 429$ million & Brown et al. (2013) \\
$C^{B}$ & $\$ 58.5 /$ dry metric ton & OEERE (2011) \\
$C^{O}$ & $\$ 1.091 /$ gallon & Brown et al. (2013) \\
$C^{H}$ & $\$ 0.26 /$ ton-mile & BTS (2012) \\
$C^{F}$ & $\$ 0.26 /$ ton-mile & BTS (2012) \\
$C^{T}$ & $\$ 0.404 /$ gallon & API (2013) \\
\hline
\end{tabular}

\subsection{The Baseline Case}

The baseline case uses all the parameter values given in Sections 4.1 and 4.2. Furthermore, we assume the planning horizon is $T=20$ years, and the investment decision is only considered in the beginning of each month in the first 5 years (i.e., $\hat{T}=5$ years). First we evaluate the investment project considering a lead time $L=12$ months. The threshold price is $H_{0}=\$ 4.48 /$ gallon at $t=0$. Assume that the initial fuel price is $P_{0}=$ $\$ 3.0 /$ gallon (the mean price level $m_{t}$ of 2015 ), the expected project value is $\$ 140.7$ million (net present value). Since the initial condition $P_{0}<H_{0}$, the optimal strategy is to invest later, and the expected waiting time is about $E[\tau]=42.0$ months. We also evaluate the project value without the delay option (i.e. invest immediately), the expected NPV is $\$ 120.4$ million. Thus, it is optimal to wait rather than to invest immediately. There are two main reasons. First, deferring the project can lower the investment costs, but also delay the revenue flows. When the gain from waiting exceeds the cost 
of the foregone revenues from delaying the investment, it is better to wait. Second, the mean level of the retail gasoline price $P_{t}$ in (16) is increasing over time based on the EIA forecast in Figure 6, which implies a potential growth in the investment value. This growth creates a value to waiting. In Figure 7, the threshold prices $H_{t}$ for the first five years are shown. It can be seen that the threshold price decreases over time, indicating that the optimal exercise condition (for building the pyrolysis facility) becomes easier to meet over time. Also considering the increasing trend of the fuel price forecasted in Figure 6, apparently there is an optimal time ahead to invest in the pyrolysis facility when the increasing gasoline price meets the declining threshold price. Since the investment expenditures are at least partially irreversible, by deferring the investment the DM retains the right to gain from building the facility in more favorable condition (with a higher gasoline price). The DM also retains the option to forego the investment if the gasoline price does not turn out to increase as forecasted. This interpretation assumes there is no competition in supplying the same type of cellulosic biofuels.

The risk associated with the investment is shown in Figure 8. The frequency chart in Figure 8 is obtained using the Monte Carlo simulation described in Section 3. The optimal investment time can also be obtained from the same simulation. Figure 9 shows the frequency chart of the investment time $\tau$. It can be seen that the distribution of the project value is bell-shaped. The Value-at-Risk (VaR) highlighted in Figure 8 shows that the DM has a $10 \%$ chance of losing more than $\$ 67.3$ million, while having $79.0 \%$ chance to 


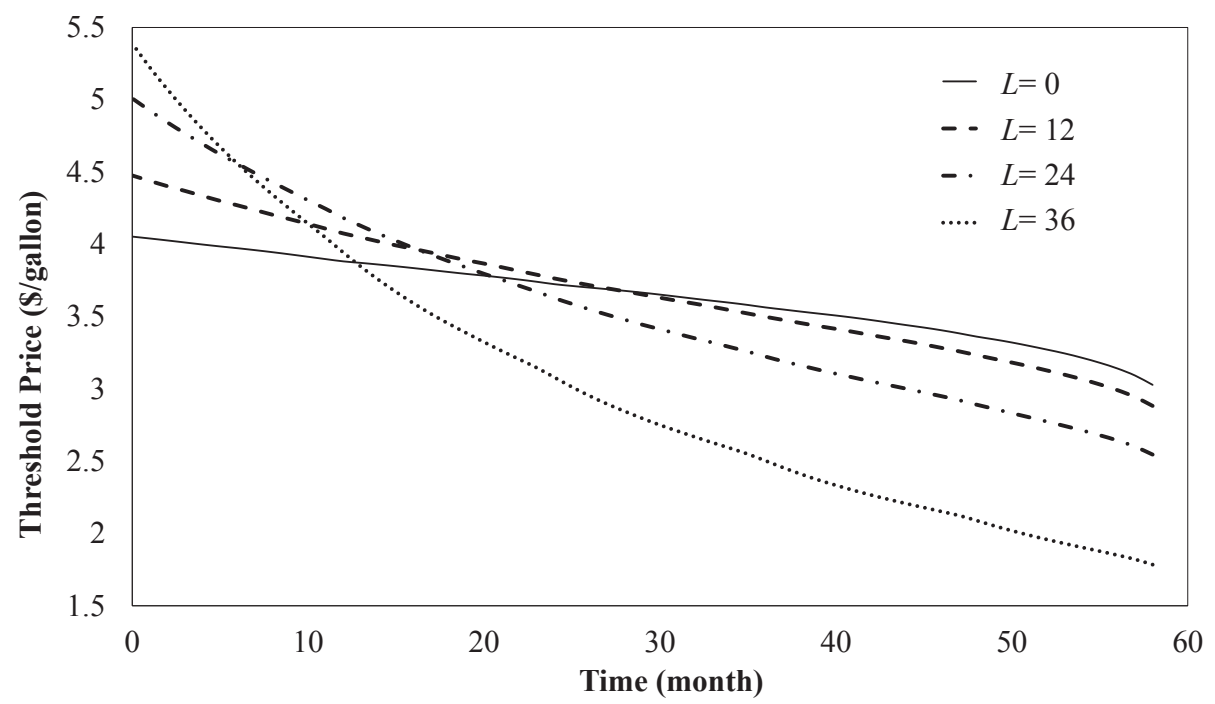

Figure 7: Threshold prices over time (in the decision period)

profit from this project (with a positive project value). The distribution of $\tau$ in Figure 9 is more irregular. The probability of building the facility has a sudden increase at $\hat{T}$ because $\hat{T}$ is the last time to decide to build or to abandon. At this time, no waiting is possible and it would build as long as the project value is positive.

Table 3: Project value and investment time vs. initial price

\begin{tabular}{ccc}
\hline$P_{0}(\$ /$ gallon $)$ & $F\left(P_{0}\right)(\$$ million $)$ & $E[\tau]$ (month) \\
\hline 3.00 & 140.7 & 42.0 \\
3.50 & 142.4 & 36.1 \\
3.90 & 144.3 & 31.7 \\
4.10 & 145.6 & 26.0 \\
4.30 & 147.3 & 22.0 \\
4.40 & 148.3 & 17.2 \\
4.48 & 149.4 & 0 \\
\hline
\end{tabular}

Table 3 illustrates the idea of the threshold price at $t=0$. As the initial 


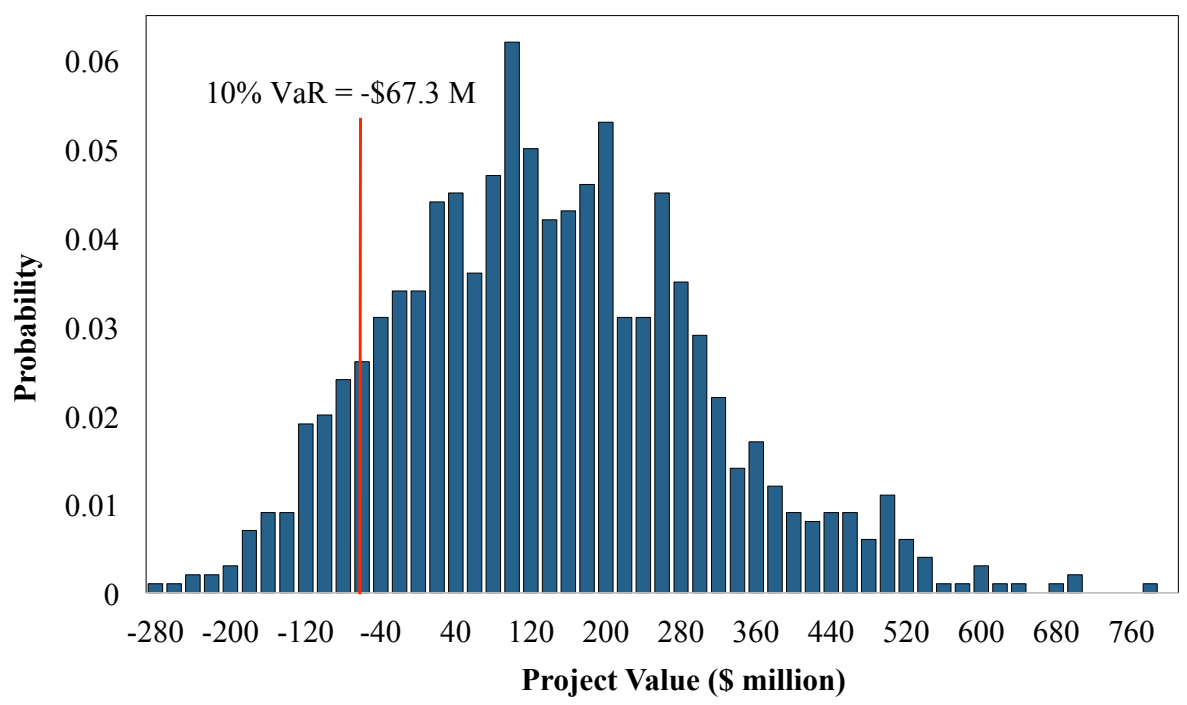

Figure 8: Frequency chart of the project value (baseline with $L=12$ months)

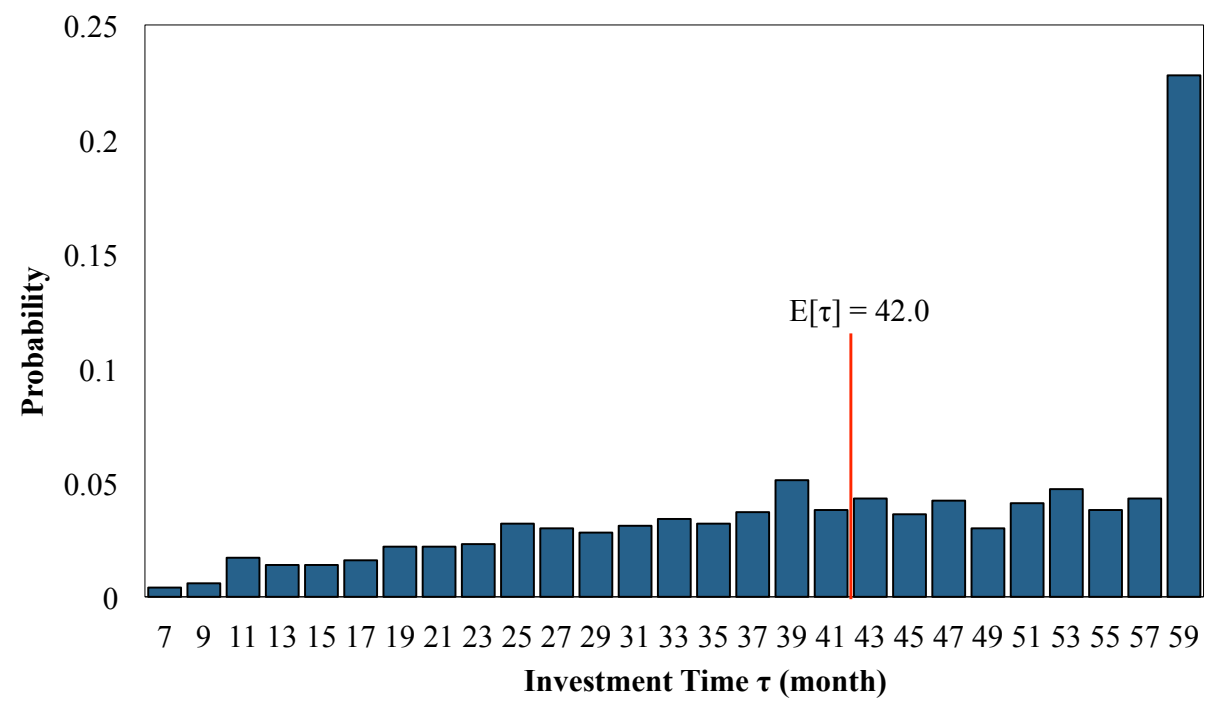

Figure 9: Frequency chart of the investment time $\tau$ (baseline with $L=12$ months)

price $P_{0}$ increases, the expected project value increases while the expected waiting time decreases. When $P_{0}$ is about $\$ 4.48 /$ gallon, the expected waiting 
time reduces to zero for the first time. This price is called the threshold price at $t=0$. As argued earlier, the threshold price is not the break-even price (its project value is positive); it is actually much greater than the break-even price.

\section{Impact of the Lead Time $L$}

In reality, a pyrolysis facility cannot be built overnight. Therefore, the impact of the lead time to the project valuation should be considered. Unfortunately, most papers using real options valuation ignore the lead time. In Table 4, we show the basic information of the project valuation by changing the length of the lead time from 0 to 36 months. In the second column of Table 4 , it shows that the project value (and the percentage change relative to the nolead-time case) decreases significantly when the lead time increases. When the lead time increases from 0 to one year, the project value depreciates to about $90 \%$ of that without lead time; at two years, it drops to $86.5 \%$. When the lead time is three years, it loses over $15 \%$ of the project value without lead time. This shows that any valuation that does not consider lead time risks inflating the project value.

Table 4 also shows that the threshold price increases with the lead time. This is reasonable because the lead time increases the risk of the investment and, therefore, the DM would require seeing a higher fuel price (and, therefore, a higher potential profit) to invest in the facility. But what is the impact of the lead time on waiting? Should the DM wait for a longer or 
shorter period when the lead time increases? Our result shows that a long lead time would actually push the DM to enter the market sooner. Because of the long lead time, the DM needs to build the facility sooner so that s/he can start collecting revenues sooner while the favorable market lasts.

This is also reflected in Figure 7, in which all curves of $H_{t}$ are decreasing, implying that as time goes, if the facility has not been built, the entry requirement becomes lower and lower. This can be interpreted as follows: At $t=0$, though the project seems highly profitable, the DM has sufficient time to optimize the entry timing to maximize the expected profit - the focus is on the entry (timing) flexibility. However, as time goes on, if the facility has not yet been built, the timing flexibility decreases (because the time to $\hat{T}$ becomes shorter), and the focus shifts to profitability rather than the flexibility. That is, ultimately the DM wants to enter the market while the profitable opportunity lasts. This situation is exacerbated when the lead time is very long, such as 36 months. In the beginning, it requires a higher $H_{0}$ to justify the risk due to the long lead time. If $P_{t}$ is never greater than $H_{t}$ to justify entry, the long delay will push the time to start collecting revenues further back, which eventually pushes the DM to enter the market while the project value is still positive. Therefore, if a project's lead time becomes longer, the DM may be required to act sooner while a favorable market lasts.

In Figure 10, we show the expected project value vs. the initial fuel price $P_{0}$. It can be seen that the project value is not only smaller when the lead time is longer; it is also less sensitive to the initial fuel price when the lead 
time is longer. In Figure 10, each curve has a turning point at its threshold price, highlighted by an $\mathrm{x}$. When the initial fuel price is greater than the threshold price, it can be seen that the project value increases much faster than otherwise. This is because the project is "in-the-money" at $t=0$ to the right side of the threshold price and is "out-of-the-money" to the left.

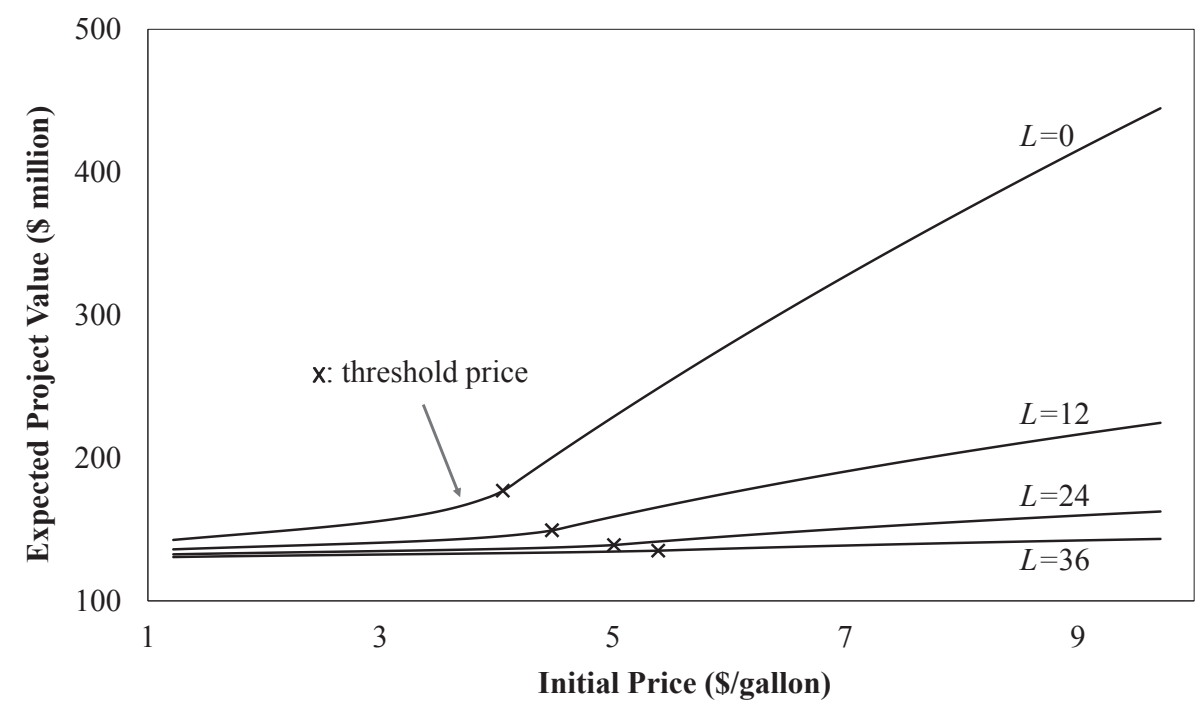

Figure 10: Project value vs. the initial fuel price 


\subsection{Impact of Price Parameters}

In this section we discuss the impact of price parameters on the project value. The three parameters in the GMR process in (16) are the mean price level $m_{t}$, reversion coefficient $\lambda$, and volatility $\sigma$. The investment is evaluated with a lead time of $L=12$ months.

By repeatedly running our programs with discrete values of $\lambda, \sigma$, and all $m_{t}$ (parallel shifted) at $\pm 10 \%$ of the corresponding values in the baseline, we use regression analysis to investigate the impact of the price parameters on the project value. Intuitively, the higher the fuel price is, the more profitable the investment becomes, which is reflected by an increase in the project value. In the regression models, we use $\Delta_{m}$ to represent the parallel shift percentage in $m_{t} ; \Delta_{\lambda}$ and $\Delta_{\sigma}$ are the percentage changes in $\lambda$ and $\sigma$, respectively. The regression functions for the threshold prices at $t=0$ and the project values are obtained as follows:

$$
\begin{gathered}
H_{0}\left(\Delta_{\lambda}, \Delta_{\sigma}, \Delta_{m}\right)=\alpha_{0}+\alpha_{1} \Delta_{m}+\left(\alpha_{2} \Delta_{m}+\alpha_{3} \Delta_{m}^{2}\right) \Delta_{\lambda}+\left(\alpha_{4} \Delta_{m}+\alpha_{5} \Delta_{m}^{2}\right) \Delta_{\sigma}+ \\
\gamma\left(\Delta_{m}-m_{h}\right)^{+}+\epsilon \\
F\left(\Delta_{\sigma}, \Delta_{m} ; P_{0}=3.0\right)=\beta_{0}+\beta_{1} \Delta_{m}+\beta_{2} \Delta_{m}^{2}+\left(\beta_{3} \Delta_{m}+\beta_{4} \Delta_{m}^{2}\right) \Delta_{\sigma}+ \\
\eta\left(\Delta_{m}-m_{f}\right)^{+}+\varepsilon
\end{gathered}
$$

where $\epsilon$ and $\varepsilon$ are mutually independent normal distributions, each with a zero mean. The values of the coefficients in the regression functions can be 
found in Table 5. In general, a positive $\Delta_{\lambda}$ means that any price deviation from the mean lasts for a shorter time period, and a negative $\Delta_{\sigma}$ represents smaller price variability. It can be seen from (17) that the project value shows that both positive $\Delta_{\lambda}$ and negative $\Delta_{\sigma}$ would increase the threshold price and decrease the project value. These suggest that the investment in a pyrolysis plant is more favorable in a more volatile fuel market. However, compared to the influence of $m_{t}, \lambda$ and $\sigma$ have far less impact. The impact of $\lambda$ and $\sigma$ are shown to be independent of each other in the regression function (17), yet highly interacted with the mean price level $m_{t}$. A positive $\Delta_{m}$ gives $\lambda$ and $\sigma$ larger influence in the threshold price and the project value. The impact of $\lambda$ on project value is almost negligible, thus no terms with $\Delta_{\lambda}$ are denoted in (18).

When the mean price level $m_{t}$ is shifted down in parallel to some extent, it would trigger a change in the investment decision (from invest to do-notinvest), which is captured by the non-negative operator terms $\left(x^{+}\right)$involving $m_{h}$ and $m_{f}$ in (17) and (18), respectively. We have estimated that $m_{h}=$ -0.071 and $m_{f}=-0.068$, and the values of both $m_{h}$ and $m_{f}$ are very close, indicating a very consistent approximation in the regression analysis. Since the profile of $m_{t}$ is largely influenced by the EIA forecast (in Figure 6), this means that if the future retail fuel price is about $7 \%$ lower than the trend predicted by the EIA (parallel shift), the project is no longer profitable. The effect of changing $m_{t}$ (parallel shift) on the threshold price and the project value is given in Figure 11. Each of the two curves in Figure 11 
appears to have a turning point when the parallel shift in $m_{t}$ is at about $-7 \%$, corresponding to the values of $m_{h}$ and $m_{f}$ in the regression models (17) and (18), respectively. Again, this indicates that if the price outlook is about $7 \%$ lower than expected, the project should not be invested at all.

Table 5: Regression results for threshold price (\$/gallon) and expected project value (\$ million) vs. price parameters

\begin{tabular}{cccccccccc}
\hline$\alpha_{0}$ & $\alpha_{1}$ & $\alpha_{2}$ & $\alpha_{3}$ & $\alpha_{4}$ & $\alpha_{5}$ & $\gamma$ & $m_{h}$ & $\mathrm{sd}^{\dagger}$ & $R^{2}$ \\
\hline-11.5 & -205 & -437 & 6103 & 122 & -1520 & 197 & $-7.1 \mathrm{e}-2$ & 3.1 & 0.82 \\
\hline$\beta_{0}$ & $\beta_{1}$ & $\beta_{2}$ & $\beta_{3}$ & $\beta_{4}$ & & $\eta$ & $m_{f}$ & $\mathrm{sd}^{\dagger}$ & $R^{2}$ \\
\hline 45.2 & 891 & 4290 & 811 & 9134 & & 1477 & $-6.8 \mathrm{e}-2$ & 14.3 & 0.99
\end{tabular}

$\dagger$ : Residual standard deviation

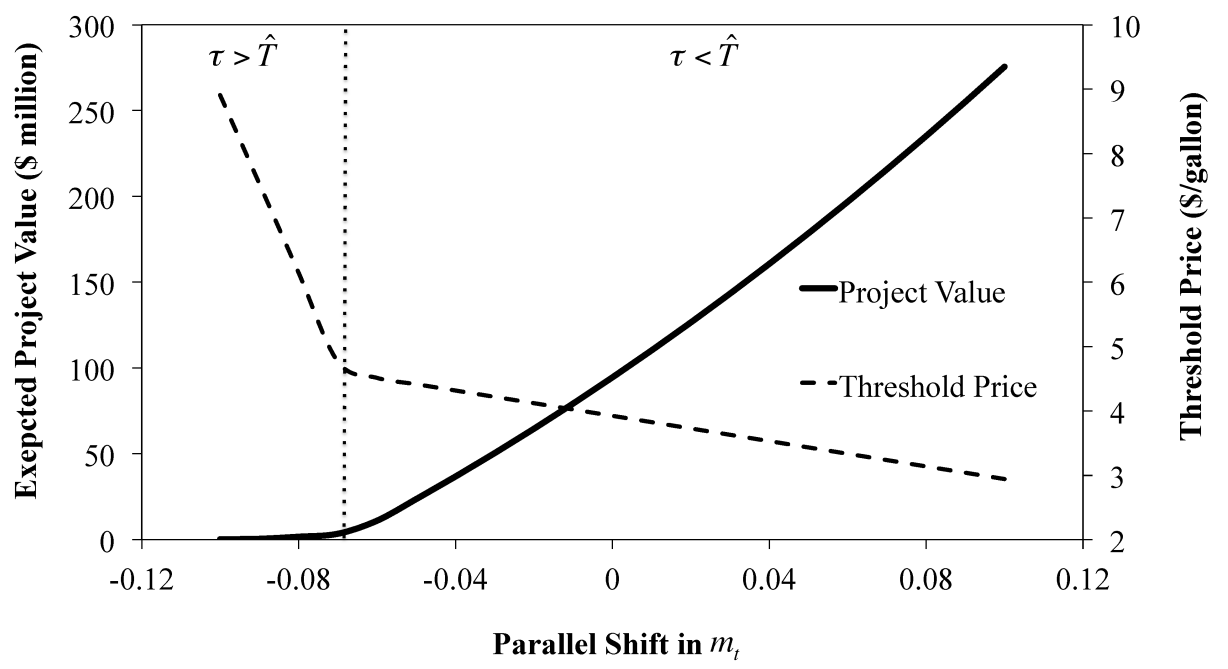

Figure 11: Threshold price (\$/gallon) and expected project value (\$ million) vs. parallel shift in $m_{t}$ 


\subsection{Impact of Process Parameters}

Biomass feedstock price and production yield are two major factors in the production process that are influential to the investment decision. For a large-scale facility (2000 metric ton/day in our case), a slight increase in the feedstock price could mean a significant increase in the production cost. Likewise, the production yield, referring to the efficiency of the new technology, could also have an impact on the revenue and the conversion cost. According to Wright et al. (2010) and Brown et al. (2013), fast pyrolysis and further conversion to produce liquid transportation fuel is relatively immature, which leads to a high level of uncertainty in technology efficiency. Therefore, we would like to assess the impact of these two factors on the investment decision.

A polynomial form is selected for the regressions of both decisions: "do not invest" $(n=0)$ within planning horizon and "invest" $(n=1)$. Let $Y$ be the process conversion rate $Y=\theta_{1} \theta_{2}$, and $C^{B}$ be the biomass feedstock price. The regression functions for both the threshold price at $t=0$ and the project value are as follows.

$$
\begin{gathered}
H_{0}\left(Y, C^{B}\right)=a_{n 1}+a_{n 2} Y+a_{n 3} C^{B}+a_{n 4} Y^{2}+a_{n 5}\left(C^{B}\right)^{2}+a_{n 6} Y C^{B}+\epsilon_{n} \\
F\left(Y, C^{B} ; P_{0}=3.0\right)=\begin{array}{ll}
b_{n 1}+b_{n 2} Y+b_{n 3} C^{B}+b_{n 4} Y^{2}+b_{n 5}\left(C^{B}\right)^{2}+ \\
& b_{n 6} Y C^{B}+\varepsilon_{n}
\end{array}
\end{gathered}
$$


where the residual terms, $\epsilon_{n}$ and $\varepsilon_{n}$, are each independent normal distributions with means of zero and standard deviations of $\sigma_{1 n}$ and $\sigma_{2 n}$, respectively, for $n=1,2$. The regression parameters and the statistical measures of the fitting are given in Table 6 .

Table 6: Regression results for threshold price (\$/gallon) and the project value (\$ million)

\begin{tabular}{cccccccccc}
\hline$n$ & $a_{n 1}$ & $a_{n 2}$ & $a_{n 3}$ & $a_{n 4}$ & $a_{n 5}$ & $a_{n 6}$ & $\hat{\sigma}_{1 n}$ & $R^{2}$ & MAPE $^{\dagger}$ \\
\hline 0 & $1.8 \mathrm{e}+3$ & $-1.9 \mathrm{e}+4$ & $1.5 \mathrm{e}+1$ & $4.9 \mathrm{e}+4$ & $3.0 \mathrm{e}-2$ & $-7.9 \mathrm{e}+1$ & 0.7 & 1.00 & 0.025 \\
1 & $9.1 \mathrm{e}+1$ & $-7.7 \mathrm{e}+2$ & $7.2 \mathrm{e}-1$ & $1.7 \mathrm{e}+3$ & $1.3 \mathrm{e}-3$ & -3.0 & 0.1 & 0.99 & 0.013 \\
\hline$n$ & $b_{n 1}$ & $b_{n 2}$ & $b_{n 3}$ & $b_{n 4}$ & $b_{n 5}$ & $b_{n 6}$ & $\hat{\sigma}_{2 n}$ & $R^{2}$ & $\mathrm{MAE}^{\ddagger}$ \\
\hline 0 & 3.6 & $-5.1 \mathrm{e}+2$ & $5.2 \mathrm{e}-1$ & $1.7 \mathrm{e}+3$ & $1.1 \mathrm{e}-3$ & -3.1 & 0.4 & $0.38^{\S}$ & 0.28 \\
1 & $-1.1 \mathrm{e}+2$ & $-5.3 \mathrm{e}+3$ & 7.3 & $3.4 \mathrm{e}+4$ & $4.8 \mathrm{e}-2$ & $-8.0 \mathrm{e}+1$ & 0.7 & 1.0 & 3.79 \\
\hline
\end{tabular}

$\dagger$ : Mean Absolute Percentage Error

$\ddagger$ : Mean Absolute Error

$\S: R^{2}$ is very small in this "do not invest" case because the expected project value is close to 0 .

The regression models are selected based on the statistical measure of $R^{2}$, one-way analysis of variance (ANOVA) significance tests, and satisfactory Mean Absolute Percentage Error (MAPE) or Mean Absolute Error (MAE). The regression of the threshold price and the expected project value are illustrated in Figure 12. The dashed line in each figure illustrates the "indifference" boundary. On one side of the boundary, Region A represents the region in which investing in the project is favorable, and on the other side, Region B represents the region where the DM should not invest.

Intuitively, the project would be very profitable when the conversion rate 


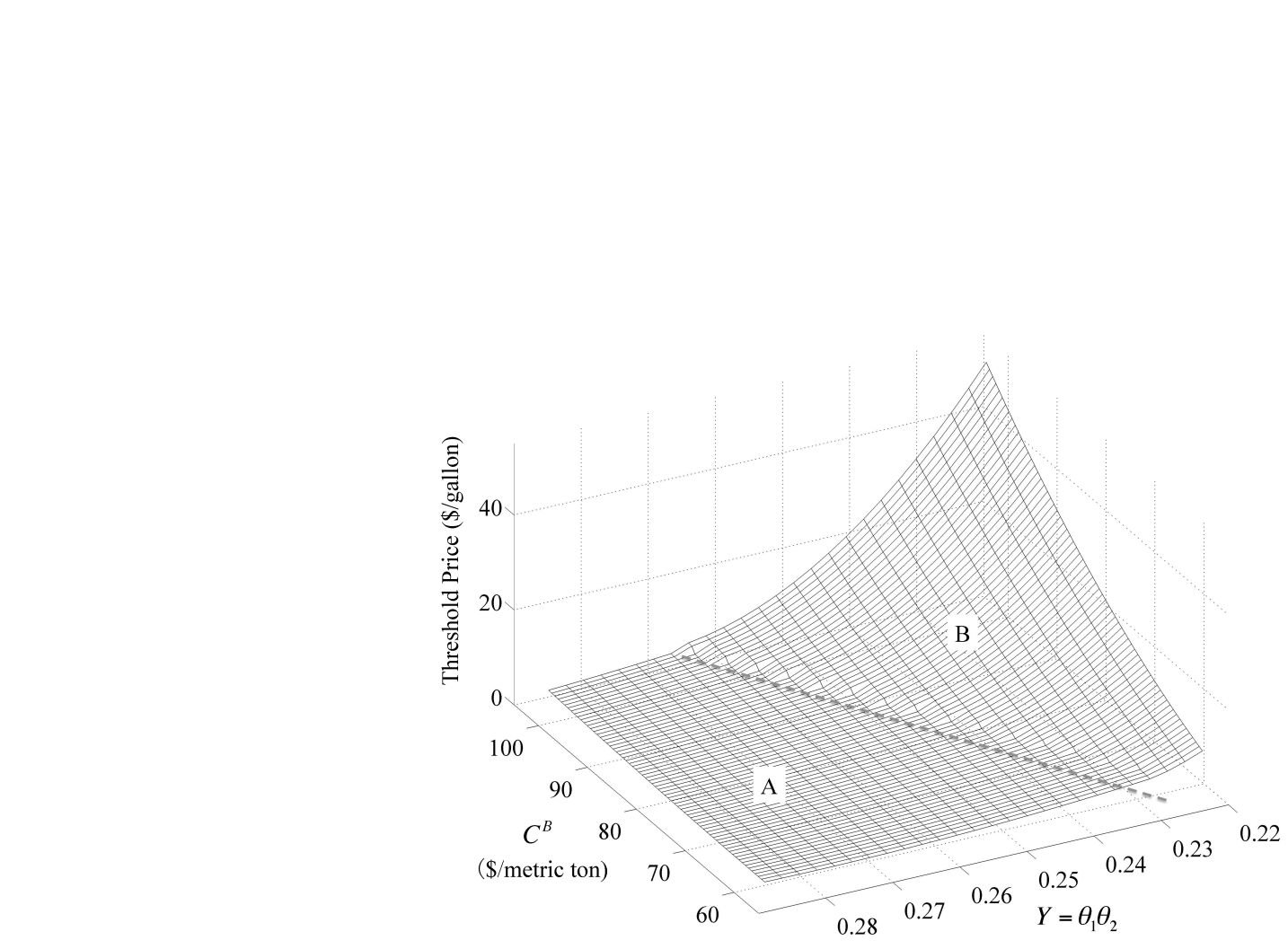

(a) Threshold Price



(b) Expected Project Value

Figure 12: Regression of threshold price and the expected project value on conversion rate and biomass price 
is high and the biomass feedstock price is low (Region A in Figure 12). The significance of the interaction term $\left(Y C^{B}\right)$ in the regression models shows that the two factors, biomass feedstock price and the conversion rate, do not affect the investment decision independently. The effects of the conversion rate on the threshold price and the project value are much greater than that of the biomass feedstock price. The indifference boundary highlighted in Figure 12 shows the trade-off relation between these two factors. Basically, every $1 \%$ increase in the biomass feedstock price can be offset by a $0.25 \%$ increase of the conversion rate. This result can be used to price long-term contracts of biomass feedstock to ensure profitability given a conversion rate.

\subsection{Impact of Other Factors}

Thus far we have discussed how the factors of fuel price, production yield, and feedstock price impact the investment value and timing. There are two other factors that are also relevant to the investment decision-making: project finance and biomass supply chain. In project finance, a capital structure has an implication on project (construction) risks and long-term profitability. On the other hand, supply chain uncertainties, including feedstock availability and logistic costs, if not managed well, can be detrimental to the facility's day-to-day operations. These factors, to some degree, all contribute to the project value and influence the investment timing. To analyze their impacts on the project value requires specific, technical knowledges, and is outside the scope of this paper. However, we can roughly discuss how they 
affect the investment timing.

In general, a factor that can contribute to the increase of the project value tends to induce a quicker investment, i.e., reduce waiting, and vice versa. Therefore, a higher cost of capital will increase the project cost and lower the project value. It will also delay the investment because it will require a higher threshold price to ensure profitability. Likewise, higher supply chain costs (e.g., low availability of feedstock and high transportation costs) will contribute to the increase of operating costs and the decrease the project value, which increases waiting. We hope to incorporate these factors to the valuation in future research.

\section{Conclusions}

In this paper, a real options approach has been proposed to value a fast pyrolysis facility investment under fuel price uncertainty. We intended to answer the question whether now is a good time for Iowa to start investing in cellulosic biofuels. Given that the fuel price outlook is very positive as forecasted by the Energy Information Administration (EIA), the investment in general is very profitable with manageable risks (about $80 \%$ chance to be profitable). However, our valuation model also indicates that the trigger price for an immediate investment is $\$ 4.48 /$ gallon, which suggests the decision maker should invest later to maximize the net profit. Our result also indicates that the construction lead time is too important to ignore. When the lead 
time increases from 0 to one year, the project value is $10 \%$ lower; at two years, $13.5 \%$ lower. This result suggests that a speedy permitting approval process of the facility construction by government can increase the project value and may induce investments. Using regression we also show how technology improvement in production yield may increase the project value and offset the effects from biomass feedstock price change.

\section{Acknowledgments}

This study was partially supported by the Biomass Program from the U.S. Department of Energy.

\section{Appendix. Constructing a Trinomial Lattice}

Next we briefly describe how the risk neutral probabilities are obtained, which is based on Tseng and Lin (2007). To simplify the notation, we consider the following general stochastic process under the risk-neutral space:

$$
d y=\mu(y, t) d t+\sigma d B,
$$

where $B$ is a Wiener process. To apply (A1) to the risk-neutral process of (16), one can have $y=\ln P_{t}$ and $\mu(y, t)=\lambda_{t}\left(m_{t}-\left(r_{a}-r_{f}\right) / \lambda_{t}-y\right)$.

To describe the lattice, we use the notation node $(j, t)$ to represent the $j$-th node at time $t$, corresponding to a price $y_{j, t}$ and a drift $\mu_{j, t}=\mu\left(y_{j, t}, t\right)$. Denote 
the price jump of the lattice as a constant $\Delta y$, which equals to $y_{j+1, t}-y_{j, t}$, for any node $(j, t)$. Following Hull and White (1993), $\Delta y$ is set to be $\sigma \sqrt{3 \Delta t}$.

The idea of the trinomial lattice is that any arbitrary node $(j, t)$ maps to three adjacent nodes $\left(j+\kappa_{j, t}+1, t+\Delta t\right),\left(j+\kappa_{j, t}, t+\Delta t\right)$, and $\left(j+\kappa_{j, t}-\right.$ $1, t+\Delta t)$ in the next time period $t+\Delta t$, where $\kappa_{j, t}$ is selected such that $\kappa_{j, t} \Delta y$ approximates the expected price deviation $\mu_{j, t} \Delta t$ with

$$
\kappa_{j, t}=\operatorname{nint}\left(\frac{\mu_{j, t} \Delta t}{\Delta y}\right),
$$

where $\operatorname{nint}(x)$ is the function that rounds $x$ to the nearest integer. When $x$ is a half integer, the function rounds up (e.g., $\operatorname{nint}(1.5)=2$ ). At each discrete time $t$, we have the following approximation of the diffusion:

$$
\begin{aligned}
E[y(t+\Delta t)] & =y(t)+\mu(y, t) \Delta t \\
V[y(t+\Delta t)] & =E\left[y(t+\Delta t)^{2}\right]-E[y(t+\Delta t)]^{2}=\sigma^{2} \Delta t
\end{aligned}
$$

At node $(j, t)$, the branching probabilities $p_{j, t}^{u}, p_{j, t}^{m}, p_{j, t}^{d}$ are determined to match the first two moments of the price change at $y_{j, t}$ as follows.

$$
\begin{gathered}
p_{j, t}^{u}\left(\kappa_{j, t}+1\right) \Delta y+p_{j, t}^{m} \kappa_{j, t} \Delta y+p_{j, t}^{d}\left(\kappa_{j, t}-1\right) \Delta y=\mu_{j, t} \Delta t \\
p_{j, t}^{u}\left(\kappa_{j, t}+1\right)^{2}(\Delta y)^{2}+p_{j, t}^{m} \kappa_{j, t}^{2}(\Delta y)^{2}+p_{j, t}^{d}\left(\kappa_{j, t}-1\right)^{2}(\Delta y)^{2}= \\
\mu_{j, t}^{2}(\Delta t)^{2}+\sigma^{2} \Delta t \\
p_{j, t}^{u}+p_{j, t}^{m}+p_{j, t}^{d}=1
\end{gathered}
$$


The solution of $(\mathrm{A} 5)-(\mathrm{A} 7)$ is

$$
\begin{aligned}
& p_{j, t}^{u}=\frac{1}{2}\left(\frac{1}{3}+\left(\frac{\mu_{j, t} \Delta t}{\Delta y}-\kappa_{j, t}\right)+\left(\frac{\mu_{j, t} \Delta t}{\Delta y}-\kappa_{j, t}\right)^{2}\right) \\
& p_{j, t}^{d}=\frac{1}{2}\left(\frac{1}{3}-\left(\frac{\mu_{j, t} \Delta t}{\Delta y}-\kappa_{j, t}\right)+\left(\frac{\mu_{j, t} \Delta t}{\Delta y}-\kappa_{j, t}\right)^{2}\right) \\
& p_{j, t}^{m}=1-p_{j, t}^{u}-p_{j, t}^{d}
\end{aligned}
$$

It can be shown that $p_{j, t}^{u}, p_{j, t}^{m}$ and $p_{j, t}^{d}$ are always between 0 and 1 (Tseng and Lin 2007).

\section{References}

American Petroleum Institute (API), 2013. http://www.api.org/Oil-andNatural-Gas-Overview/Industry-Economics/Fuel-Taxes.aspx [accessed: Dec. 2013].

Babu, B.V., 2008. Biomass pyrolysis: a state-of-the-art review. Biofuels, Bioproducts and Biorefining, 2(5):393-414.

Bengtsson, J., Olhager, J., 2002. Valuation of product-mix flexibility using real options. International Journal of Production Economics, 78(1):1328.

Bridgwater, A. V., 1999. Fast pyrolysis of biomass: a handbook. Vol 1. CPL Press, Newbury, Berkshire, UK 
Bridgwater, A. V., 2002. Fast pyrolysis of biomass: a handbook. Vol 2. CPL Press, Newbury, Berkshire, UK

Bridgwater, A. V., 2005. Fast pyrolysis of biomass: a handbook. Vol 3. CPL Press, Newbury, Berkshire, UK

Bockman, T., Fleten, S.E., Juliussen, E., Langhammer, H.J., Revdal, I., 2008. Investment timing and optimal capacity choice for small hydropower projects. European Journal of Operational Research, 190(2008):255-267.

Boomsma, T.K., Meade, N., Fleten, S.E., 2012. Renewable energy investments under different support schemes: A real options approach. European Journal of Operational Research, 220(2012):225-237.

Brown, T. R., Thilakaratne R., Brown, R. C., Hu, G., 2013. Technoeconomic analysis of biomass to transportation fuels and electricity via fast pyrolysis and hydroprocessing. Fuel, 106:463-469.

Bureau of Labor Statistics (BLS), 2014. http://www.bls.gov/data/inflation_calculator.htm [accessed: Feb. 2014].

Bureau of Transportation Statistics (BTS), 2012. Average freight revenue per ton-mile. (http://www.rita.dot.gov/bts/sites/rita.dot.gov.bts/files/ publications/national_transportation_statistics/html/table_03_21.html).

Chen, Y., Tseng, C. L., 2011. Inducing clean technology in the electricity 
sector: Trading permits or carbon tax policies? The Energy Journal, $32(3): 169-174$.

Congressional Budget Office (CBO), 1982. Energy use in freight transportation.

Congressional Research Service (CRS), 2013. Renewable fuel standard (RFS): Overview and issues.

Cook, J. A., Lin, C.-Y.C., 2014. Wind turbine shutdowns and upgrades in Denmark: Timing decisions and the impact of government policy. Working paper, University of California at Davis.

Cortazar, G., Schwartz E.S., Salinas M., 1998. Evaluating environmental investments: A real options approach. Management Science, 44(8):10591070.

Dimakopoulou, A.G., Pramatari, K.C., Tsekrekos, A.E., 2014. Applying real options to IT investment evaluation: The case of radio frequency identification (RFID) technology in the supply chain. International Journal of Production Economics, 156:191-207.

Dixit, A. K., Pindyck, R. S., 1994. Investment under Uncertainty, Princeton.

Energy Information Administration (EIA), 2010. Annual energy outlook 2010 with projections to 2035. http://www.eia.gov/oiaf/archive/aeo10/ demand.html [accessed: Feb. 2014]. 
Energy Information Administration (EIA), 2013a. http://www.eia.gov/dnav /pet/pet_pri_gnd_a_epm0_pte_dpgal_a.htm [accessed: Nov. 2013].

Energy Information Administration (EIA), 2013b. http://www.eia.gov/oiaf /aeo/tablebrowser/ [accessed: Nov. 2013].

Energy Information Administration (EIA), 2013c. http://www.eia.gov/state /data.cfm?sid=IA\#Consumption. [accessed: May 2013].

Environmental Protection Agency (EPA), 2010. Regulation of fuels and fuel additive changes to renewable fuel standard program; final rule. Federal Register 2010; Vol. 75.

Huchzermeier, A., Loch, C.H., 2001. Project management under risk: Using the real options approach to evaluate flexibility in R\&D. Management Science, 47(1):85-101.

Hull, J.C., White, A., 1993. One-factor interest-rate models and the valuation of interest-rate derivatives securities. Journal of Financial and Quantitative Analysis, 28(2):235-254.

Lee, S. C., Shih, L. H., 2010. Renewable energy policy evaluation using real option model - The case of Taiwan. Energy Economics, 32(1):S67-S78.

Li, Y., Brown, T., Hu, G., 2014. Optimization Model for a Thermochemical Biofuels Supply Network Design. Journal of Energy Engineering, 10.1061/(ASCE)EY.1943-7897.0000158, 04014004. 
Lin, C.-Y.C., Thome, K., 2014. Investment in corn-ethanol plants in the midwestern United States: An analysis using reduced-form and structural models. Working paper, University of California at Davis.

Lin, C.-Y.C., Yi, F., 2014a. Ethanol plant investment in Canada: A structural model. Working paper, University of California at Davis.

Lin, C.-Y.C., Yi, F., 2014b. What factors affect the decision to invest in a fuel ethanol plant?: A structural model of the ethanol investment timing game. Working paper, University of California at Davis.

Maxwell, C., Davison, M., 2014. Using real option analysis to quantify ethanol policy impact on the firm's entry into and optimal operation of corn ethanol facilities. Energy Economics, 42(2014):140-151.

Office of Energy Efficiency and Renewable Energy (OEERE), U.S. Department of Energy, 2011. Multi-year Program plan. Washington, DC: U.S. Department of Energy, April 2011.

Piskorz, J., Radlein, D., Scott, D. S., Czernik, S., 1988. Liquid products from the fast pyrolysis of wood and cellulose. Research in Thermochemical Biomass Conversion, 557-571.

Schmit, T.M., Luo, J. Conrad, J.M., 2011. Estimating the Influence of US ethanol policy on plant investment decisions: A real options analysis with two stochastic variables. Energy Economics, 33(2011):1194-1205. 
Schwartz, E., and Smith, J.E., 2000. Short-term variations and long-term dynamics in commodity prices. Management Science, 46(7):893-911.

Swanson, R. M., Satrio, J. A., Brown, R. C., Platon, A., Hsu, D. D., 2010. Techno-economic analysis of biofuels production based on gasification. National Renewable Energy Laboratory, Golden, CO.

Tseng, C. L., Barz G., 2002. Short-term generation assest valuation: A real options approach. Operations Research, 50(2):297-310.

Tseng, C. L., Lin, K.Y., 2007. A framework using two-factor price lattices for generation asset valuation. Operations Research, 55(2):234-251.

U.S. Census Bureau, 2013. http://www.census.gov/population/metro/data /metrodef.html [accessed: Feb. 2013].

U.S. Department of the Treasury, 2014. http://www.treasury.gov/resourcecenter/data-chart-center/interest-rates/Pages/TextView.aspx?data=yield [accessed: Dec. 2014].

Wright, M. M., Daugaard, D. E., Satrio, J. A., Brown, R. C., 2010. Technoeconomic analysis of biomass fast pyrolysis to transportation fuels. Fuel, 89(1):S2-S10.

Yi, F., Lin, C.-Y.C., Thome, K., 2014. An Analysis of the Effects of Government Subsidies and the Renewable Fuels Standard on the Fuel Ethanol Industry: A Structural Econometric Model. Working paper, University of California at Davis. 